\title{
Primary Afferent Depolarization and Frequency Processing in Auditory Afferents
}

\author{
Tom Baden and Berthold Hedwig \\ Department of Zoology, University of Cambridge, Cambridge CB2 3EJ, United Kingdom
}

Presynaptic inhibition is a widespread mechanism modulating the efficiency of synaptic transmission and in sensory pathways is coupled to primary afferent depolarizations. Axonal terminals of bush-cricket auditory afferents received $2-5 \mathrm{mV}$ graded depolarizing inputs, which reduced the amplitude of invading spikes and indicated presynaptic inhibition. These inputs were linked to a picrotoxin-sensitive increase of $\mathrm{Ca}^{2+}$ in the terminals. Electrophysiological recordings and optical imaging showed that in individual afferents the sound frequency tuning based on spike rates was different from the tuning of the graded primary afferent depolarizations. The auditory neuropil of the bush-cricket Mecopoda elongata is tonotopically organized, with low frequencies represented anteriorly and high frequencies represented posteriorly. In contrast graded depolarizing inputs were tuned to high-frequencies anteriorly and to low-frequencies posteriorly. Furthermore anterior and posterior axonal branches of individual afferents received different levels of primary afferent depolarization depending on sound frequency. The presence of primary afferent depolarization in the afferent terminals indicates that presynaptic inhibition may shape the synaptic transmission of frequency-specific activity to auditory interneurons.

\section{Introduction}

Presynaptic inhibition is a fundamental mechanism regulating the strength of synaptic transmission in vertebrates and invertebrates. In most cases a local GABA-mediated increase of the $\mathrm{Cl}^{-}$ conductance shunts the membrane close to axonal terminals (for review, see Watson et al., 2005). As a consequence the amplitude of spikes invading the axon terminals is decreased; which in turn reduces the presynaptic $\mathrm{Ca}^{2+}$ entry. This leads to a reduction in the amount of transmitter released, and thereby evokes smaller postsynaptic potentials (Boyan, 1988; Burrows and Matheson, 1994). Depending on the local $\mathrm{Cl}^{-}$concentration and the resting membrane potential in the presynaptic neuron the increase of the $\mathrm{Cl}^{-}$conductance can manifest as a graded depolarization of the membrane potential, called primary afferent depolarization (PAD). In insects and crustaceans PADs linked to presynaptic inhibition have been analyzed in the context of both motor and sensory processing (for review, see Clarac and Cattaert, 1996, 1999; Watson, 1992; Watson et al., 2005).

In populations of afferents from the same sensory organ, presynaptic inhibition may act as a gain control mechanism, limiting excitation and activity forwarded to central neurons and thus extending the dynamic range of the sensory pathway (Burrows and Matheson, 1994). In addition, presynaptic inhibition may improve the specificity of the flow of sensory information (Burrows

\footnotetext{
Received May 28, 2010; revised Aug. 29, 2010; accepted Sept. 6, 2010.

T.B. was supported by the Biotechnology and Biological Sciences Research Council. The imaging equipment was funded by the Royal Society and the Newton Trust. We thank E. A. Seyfarth, H. Römer, and A. Stumpner for generously providing the bush-crickets, and Malcolm Burrows, Steve Rogers, Jeremy Niven, Stefan Schöneich, and Kostas Kostarakos for constructive comments on the manuscript.

T. Baden's current address: MRC Laboratory of Molecular Biology, Hills Road, Cambridge CB2 OQH, UK.

Correspondence should be addressed to Berthold Hedwig, Department of Zoology, Downing Street, University of Cambridge, Cambridge CB2 3EJ, UK. E-mail: bh202@cam.ac.uk.

DOI:10.1523/JNEUROSCI.2734-10.2010

Copyright $\odot 2010$ the authors $\quad 0270-6474 / 10 / 3014862-08 \$ 15.00 / 0$
}

and Laurent, 1993; Sauer et al., 1997; Root et al., 2008). A mechanism by which the response of postsynaptic interneurons would be tuned through selective presynaptic inhibition of particular afferents may be well suited for processing in any sensory pathway, such as the processing of auditory signals in the frequency domain.

Bush-crickets Mecopoda elongata (Tettigoniidae) use complex amplitude and frequency modulated sound signals for elaborate intraspecific communication, specifically acoustically guided mate finding and predator avoidance (Bailey and Rentz, 1990; Gwynne, 2001). Ultrastructural evidence indicated that presynaptic inhibition may contribute to information processing in the prothoracic auditory neuropil (Watson et al., 2005). Close to output synapses onto local and ascending interneurons afferent terminals have input synapses from GABA-immunoreactive processes (Hardt and Watson, 1999). In many other sensory pathways such synapses indicate a presynaptic inhibitory modulation of afferent synaptic transmission. Using electrophysiological and optical recording techniques we demonstrate the presence of PADs in the terminals of bush-cricket auditory afferents and show how these are linked to frequency processing in the auditory pathway.

\section{Materials and Methods}

Bush-crickets, Mecopoda elongata, were obtained from populations kept at the Departments of Zoology in Frankfurt, Göttingen, and Graz. The animals were kept in our insect facilities at $27^{\circ} \mathrm{C}, 90 \%$ humidity and a $12 \mathrm{~h}$ light/dark cycle. Animals had constant access to food and water. Both male and female animals were used. Before experiments the bushcrickets were cold anesthetized and the wings, hind and middle legs were removed. The body was tethered ventral side up in a plasticine dish. The front legs were set up at an angle of $45^{\circ}$ and the distal tibia and the tarsi were tethered to an insect pin with low melting wax. The first thoracic ganglion was exposed for intracellular recordings. The ganglion was sup- 
A
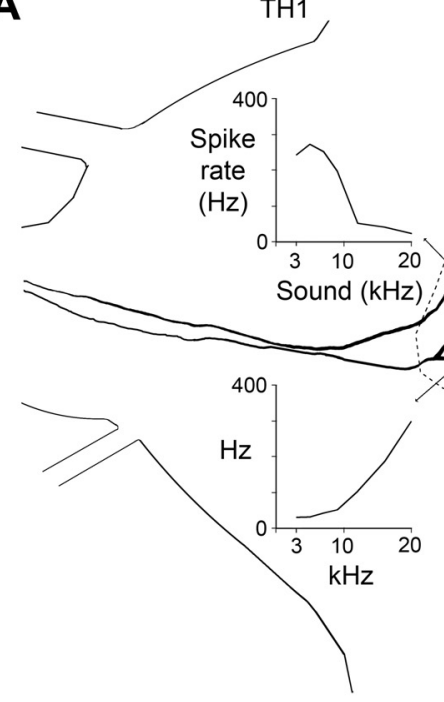

B

$$
\begin{gathered}
\text { Widefield } \\
\text { image }
\end{gathered}
$$

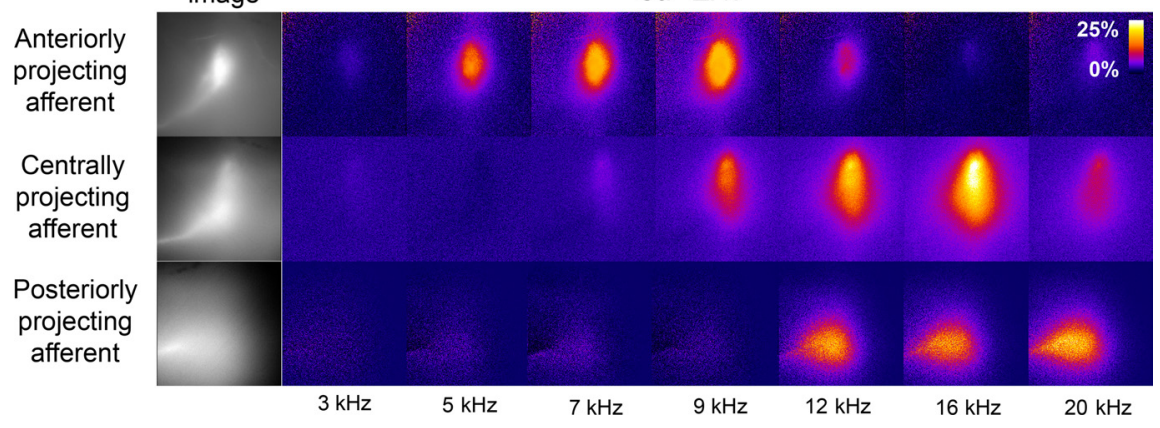

Figure 1. Tonotopic organization of the auditory neuropil. $A$, Axonal arborizations of individual low-, mid-, and high-frequency auditory afferents in the auditory neuropil of the first thoracic ganglion. Frequency tuning curves based on spike activity are shown for each afferent. $\boldsymbol{B}$, Acoustically evoked $\mathrm{Ca}^{2+}$ signals in the axonal terminals of low-, mid-, and high-frequency afferents, projecting to the anterior, middle, or posterior area of the auditory neuropil. Data based on time-averaged responses to three $1 \mathrm{~s}$ sound stimuli.

ported by a stainless steel platform and was stabilized by a small ring lowered onto the ventral surface of the ganglion. An optic fiber was used for illumination of the ganglion while positioning the electrode. All prothoracic side nerves and connectives in addition to Nerve 5, containing the auditory afferents, were cut. The ganglion was bathed in insect saline (in mM: $140 \mathrm{NaCl}, 10 \mathrm{KCl}, 4 \mathrm{CaCl}_{2}, 4 \mathrm{NaHCO}_{3}, 6 \mathrm{NaH}_{2} \mathrm{PO}_{4}$ ). Data are based on successful recordings in 97 bush-crickets at $21-23^{\circ} \mathrm{C}$.

Acoustic stimuli were generated by Cool Edit 2000 (Syntrillium, now Adobe Corp.) and played via two broadband loudspeakers (Sinus Live, Conrad Electronics) positioned, respectively, at $90^{\circ}$ to the left and right of the animal at $15 \mathrm{~cm}$ distance to the opening of the auditory spiracle. Sound intensity at the position of the animal was calibrated between 40 and $105 \mathrm{~dB}$ SPL (sound pressure level) relative to $10^{-5} \mathrm{~N} / \mathrm{m}^{2}$ using a free field microphone and measuring amplifier (type 4191 and type 2610, Bruel and Kjaer). Sound stimuli were either white noise pulses (bandwidth: $50-22,000 \mathrm{~Hz}$ ) of 1 or $3 \mathrm{~s}$ duration, suited to activate a broad range of afferents, or they were pulses of $21 \mathrm{~ms}$ duration and $21 \mathrm{~ms}$ interval, which were grouped into 6 and repeated at $250 \mathrm{~ms}$ intervals. Frequency tuning was tested with trains of sound pulses at $3,5,7,9,12,16$, and 20 $\mathrm{kHz}$, of $25 \mathrm{~ms}$ duration and $25 \mathrm{~ms}$ interval presented for $1 \mathrm{~s}$. In some cases we tested frequencies from 1 to $22 \mathrm{kHz}$ with $50 \mathrm{~ms}$ duration pulses. Envelopes of sound pulses were generated by an analog RMS device (type AD637 JD, Analog Devices) and recorded alongside the physiological data.

Electrophysiological recordings. Intracellular recordings from primary afferent neurons were obtained either at the root of Nerve 5 or directly in the auditory neuropil. Recording sites were $\sim 15-18 \mathrm{~mm}$ away from the spike generating zone in the ear. Micropipettes (type GC100F-10, Harvard Apparatus) were pulled with a horizontal puller (DMZ-Puller, Zeitz Instruments) and had a resistance of 90 $110 \mathrm{M} \Omega$, when filled with $2 \mathrm{M} \mathrm{KAc}$ and of 150 $200 \mathrm{M} \Omega$ with $400 \mu \mathrm{M}$ Oregon Green 1 in 400 $\mu \mathrm{M}$ KAc. Signals were amplified 10 times (SEC10 amplifier, NPI Electronic). In initial experiments auditory afferents were stained with Lucifer yellow $\mathrm{CH}$ and their structure revealed using standard histological techniques. The primary afferent neurons of the ear could easily be identified due to their positions and characteristic auditory response properties. Ipsilateral and contralateral are used in reference to the recorded auditory afferents throughout the text.

Blockage of spiking in auditory afferents. In a subset of experiments the ipsilateral ear was removed by cutting the leg at the distal femur. In another approach a miniature Peltier device (Peltron $\mathrm{GmbH}$ ) was used to reversibly block spike generation in the ipsilateral ear. The femur-tibia joint of the front leg was positioned on the Peltier element. Leg movements were prevented by waxing the distal tibia to a metal clamp. Cooling the femur-tibia joint and the adjacent hearing organ to $4^{\circ} \mathrm{C}$ completely blocked any spiking response of the auditory afferents within $45 \mathrm{~s}$. The temperature of the femur-tibia joint was monitored using a Type $\mathrm{K}$ thermocouple connected to a thermocouple signal conditioning IC (AD595, Analog Devices). The activity of the afferents fully recovered, as soon as they reached room temperature again.

Optical recordings. For optical recordings tips of micropipettes were back-filled with 400 $\mu \mathrm{M}$ Oregon Green BAPTA-1 (Invitrogen) dissolved in $400 \mu \mathrm{M}$ potassium acetate and shafts were filled with $1 \mathrm{M}$ potassium acetate. Afferents were intracellularly loaded with the $\mathrm{Ca}^{2+}$ indicator by applying a 1-9 nA hyperpolarizing current for 10-30 min and then left for 20-60 min to allow the dye to diffuse. Care was taken to achieve the lowest possible intracellular dye concentration that yielded detectable fluorescence.

Monochromatic light at $488 \mathrm{~nm}$ with $20 \mathrm{~nm}$ bandwidth (Optoscan Monochromator, Cairn Research) was applied through the epifluorescence port of a Leica DMLFS microscope. The illumination covered the entire prothoracic ganglion. Indicator fluorescence emission in the range of 515-560 nm was detected by a cooled EM-CCD (electron-multiplied charge-coupled device) camera (Andor iXon DV887; back illuminated, $90 \%$ quantum efficiency with single photon sensitivity at $-65^{\circ} \mathrm{C}$ ) operating at $50 \mathrm{~Hz}$ with $256 \times 256$ pixel resolution $(\times 2$ binning). In some experiments a $10 \times$ dry objective [numerical aperture (N.A.) 0.25 , working distance (W.D.) $19.5 \mathrm{~mm}$ ] was used to allow space for the microelectrode, but in most experiments a $20 \times$ water-immersion objective (N.A. 0.5, W.D. $0.8 \mathrm{~mm}$ ) was used and the electrode withdrawn (objectives from Leica). Imaging data were sampled using AQM Advance 6 software (Kinetic Imaging). All imaging analysis considered the axonal branching area of individual afferents in the auditory neuropil. Due to light scattering we could not specifically resolve the $\mathrm{Ca}^{2+}$ signal in individual small diameter axonal arborizations, which lie at a depth of up to $250 \mu \mathrm{m}$. The overall distribution of axonal arborizations, however, was clearly revealed (Sobel and Tank, 1994; Ogawa et al., 2006; Baden and Hedwig, 2007, 2009).

Data sampling and analysis. All electrophysiological data were digitized at either 10 or $20 \mathrm{kHz}$ using an AD board (PCI-MIO-16E4, National Instruments) linked to custom built software running under 
LabView 5.01 (National Instruments) and analyzed offline using Neurolab (Knepper and Hedwig, 1997). Imaging data were converted in AQM Advance 6 to be read by ImageJ 1.33u (National Institutes of Health, Bethesda, MD). $\mathrm{Ca}^{2+}$ signals shown are changes in fluorescence intensity relative to background intensity $(\Delta F / F)$ within a region of interest. All other analysis was performed using MatLab 6.5 (MathWorks).

\section{Results}

Spatial organization of auditory afferents

In the bush-cricket $M$. elongata $\sim 40$ auditory afferents project from each ear in each front leg to the auditory neuropil in the first thoracic ganglion. We tested whether the neuropil exhibits a tonotopic organization as in other species of bush-crickets (Oldfield, 1983; Römer, 1983; Römer et al., 1988; Stölting and Stumpner, 1998) by relating the frequency tuning of individual auditory afferents to their arborization patterns using both electrophysiological and optical imaging techniques.

For intraspecific acoustic communication the animals use broad-band (2-18 kHz) signals (Römer et al., 2002). To describe the frequency response of individual primary afferents we presented acoustic stimuli with a carrier frequency between 3 and $20 \mathrm{kHz}$ (see Materials and Methods). Individual receptor neurons were characterized as either low-, mid-, or high-frequency afferents which corresponded to their projection area. Anteriorly projecting afferents had a best response between 3 and $9 \mathrm{kHz}$. Posteriorly projecting afferents had a peak response at $20 \mathrm{kHz}$. Centrally projecting afferents had wider axonal arborizations than anterior and posterior afferents and had a maximum response at 9-12 $\mathrm{kHz}$ (Fig. 1A). The auditory neuropil of M. elongata is therefore tonotopically organized with a gradient of low to high frequencies from anterior to posterior regions, as in other species of bushcrickets (Römer, 1983; Stölting and Stumpner, 1998).

As presynaptic $\mathrm{Ca}^{2+}$ levels are closely linked to synaptic transmission we used optical measurements of the $\mathrm{Ca}^{2+} \Delta F / F$ signal evoked by acoustic stimulation to study the frequency tuning of 31 afferents and the spatial arrangement of their axonal projections (Fig. $1 \mathrm{~B}$ ). The $\mathrm{Ca}^{2+}$-sensitive dye revealed the course of the main neurites, the shape of the axonal branching pattern and projection area. We measured $\mathrm{Ca}^{2+}$ responses toward the same acoustic stimuli tested in electrophysiological characterization. A rise in the fluorescence signal upon acoustic stimulation was present in the axonal arborizations of all afferents. In addition when several afferent axons were loaded simultaneously with the calcium-sensitive dye the tonotopic organization of the axonal arborizations pattern was demonstrated as the response pattern shifted from anterior to posterior regions with acoustic stimulation of increasing frequency at $55 \mathrm{~dB}$ SPL (see supplemental movie, available at www.jneurosci.org).

\section{Calcium signals match spike rates}

In four experiments sequential recordings of afferent spike activity and optical recordings of the relative change in $\mathrm{Ca}^{2+}(\Delta F / F)$ were obtained from the same afferent (Fig. $2 A$ ). $\mathrm{Ca}^{2+}$ signals and mean spike rates were determined in response to acoustic stimulation with different frequencies and intensities $(3-20 \mathrm{kHz}$, 45-85 dB SPL). Plotting the peak $\mathrm{Ca}^{2+}$ signal against the mean spike rate demonstrated that independent of stimulus amplitudes or frequencies the peak amplitude of the $\mathrm{Ca}^{2+}$ signal increased

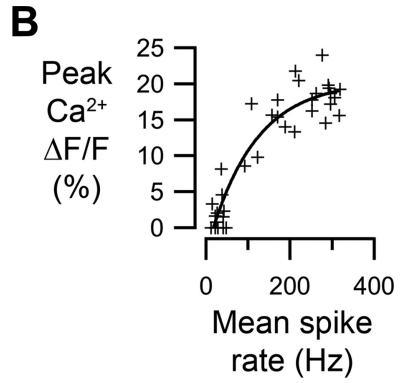

al. $A$, Spike rate and $\mathrm{Ca}^{2+}$ signal $(\Delta F / F)$ of a single afferent measured from responses to acoustic stimulation between 3 and $20 \mathrm{kHz}, 55 \mathrm{dBSPL}$ (average of three presentations). $\boldsymbol{B}$, Mean spike rate plotted against the peak amplitude of $\mathrm{Ca}^{2+}$ signals. Responses were elicited as shown in $\boldsymbol{A}$ at intensities of $45-85 \mathrm{~dB} S P L$ in $10 \mathrm{~dB}$ steps. The fit is a single exponential $\left(f(x)=a-b^{*} e^{c^{*} x}\right.$ ), where $a=20.408 \pm 1.93, b=-23.853 \pm 1.59$, and $c=$ $0.0090709 \pm 0.00267$ ( \pm indicates SD).

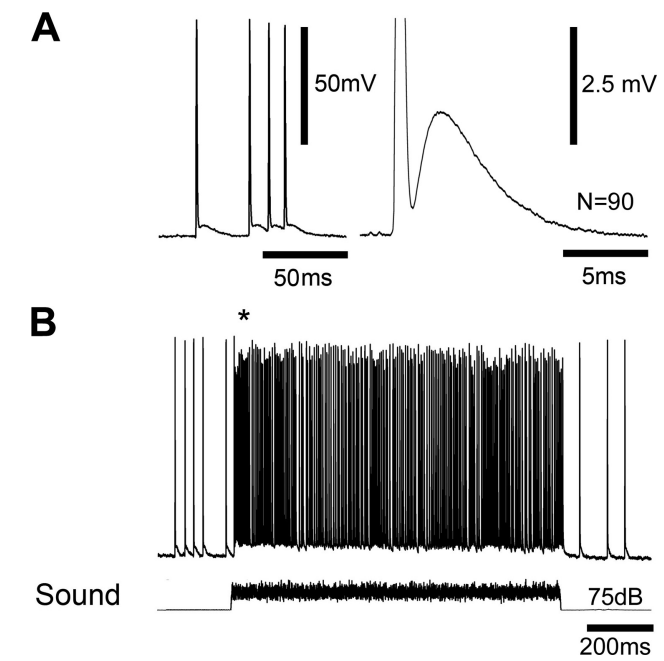

Figure 3. PADs in axonal arborizations of auditory afferents. $\boldsymbol{A}$, Graded depolarizations tightly followed spikes recorded at the entry of the auditory nerve to the first thoracic ganglion (left). Average time course of the graded depolarization following single spikes (right). $\boldsymbol{B}$, The afferent response to an acoustic stimulus (white noise, $1 \mathrm{~s}, 75 \mathrm{dBSPL}$ ) consisted of a maintained burst of spikes riding on top of a graded membrane depolarization. The asterisk highlights particularly pronounced depolarization and reduction in spike amplitude at the beginning of the response. The spike amplitude was reduced during the whole auditory response. The afferent was hyperpolarized by current injection of $-2 \mathrm{nA}$.

with the mean spike rate up to $200 \mathrm{~Hz}$ and gradually saturated at higher rates (Fig. $2 \mathrm{~B}$ ). Therefore the $\mathrm{Ca}^{2+}$ signal provides a reliable indicator of afferent mean rate of spike activity, as previously shown in crickets (Ogawa et al., 2002; Baden and Hedwig, 2007), locusts (Moreaux and Laurent, 2007) and bees (Galizia and Kimmerle, 2004).

\section{PADs in auditory afferent terminals}

In the absence of acoustic stimuli the afferents exhibited a low rate of spiking activity which was due to auditory background noise. Spike amplitudes were up to $80 \mathrm{mV}$ (Fig. $3 \mathrm{~A}$, left) and they were always accompanied by PADs of the axon membrane, indicating a very direct coupling between both events. Amplitudes of the graded depolarizations varied between 2 and $5 \mathrm{mV}$. They peaked after $3 \mathrm{~ms}$ of spike onset and decayed toward the resting membrane potential with a time constant of $4 \mathrm{~ms}$ (Fig. $3 \mathrm{~A}$, right). Such graded depolarizations of axonal terminals are closely linked with presynaptic inhibition in other mechanosensitive systems (Watson et al., 2005). Characteristic evidence for presynaptic inhibition is a reduction in spike amplitude of spikes 
A

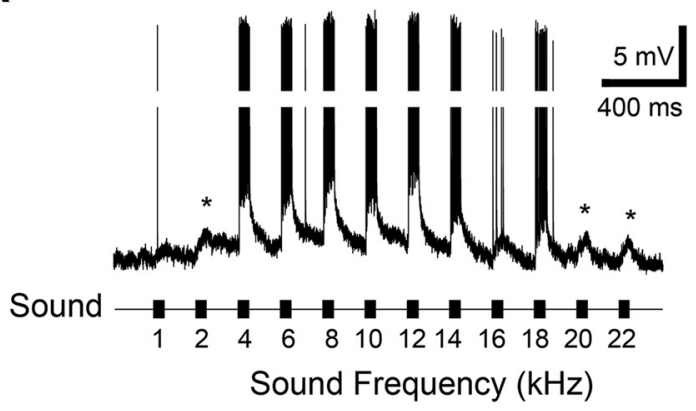

C

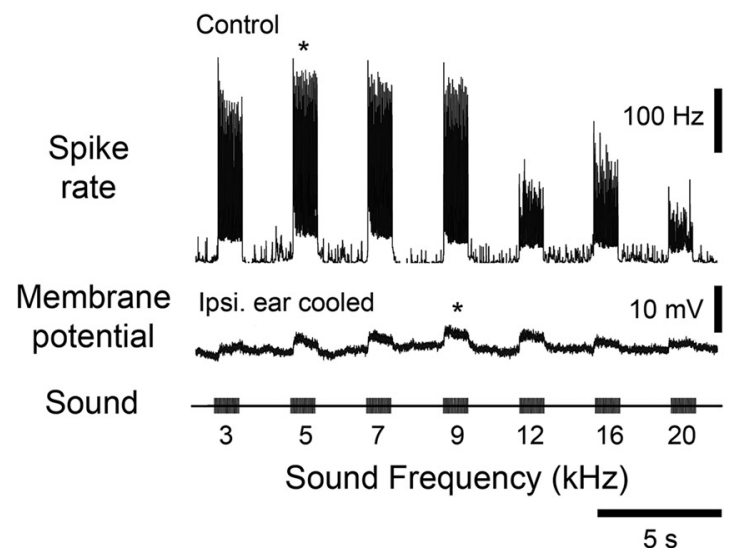

B

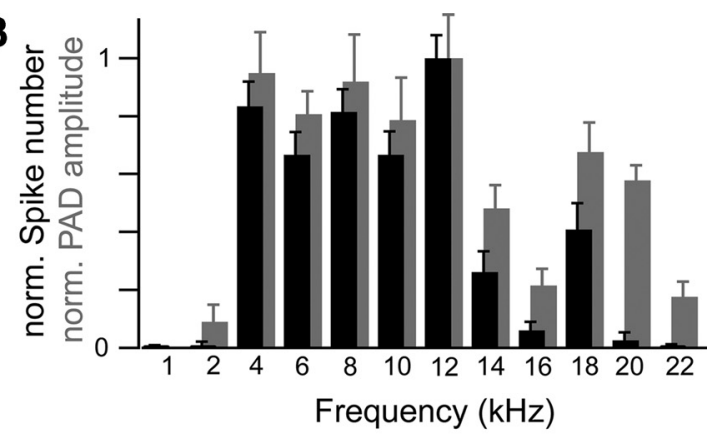

D

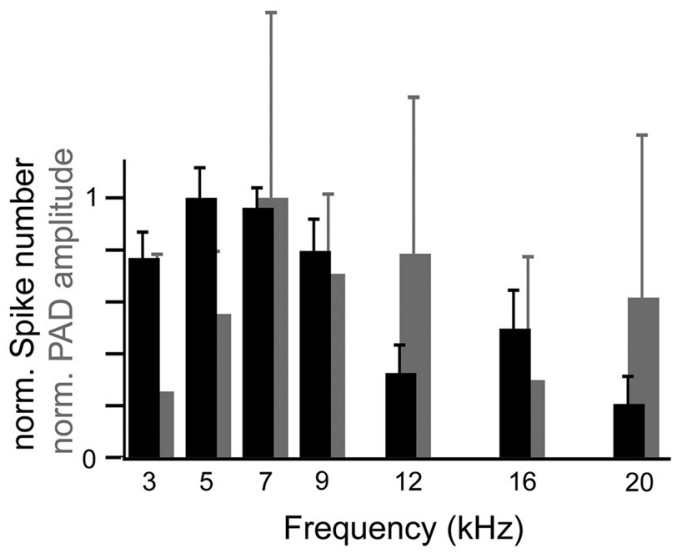

Figure 4. Graded afferent depolarization occurred independent of spike activity. $\boldsymbol{A}$, Response of a single afferent to acoustic stimulation between 1 and $22 \mathrm{kHz}$ ( $50 \mathrm{~ms}$ pulses, $75 \mathrm{~dB}$ SPL). Spikes were elicited at frequencies between 4 and $18 \mathrm{kHz}$, but graded depolarizations occurred for all frequencies tested. Asterisks highlight graded depolarizations occurring independent of spikes. To more clearly display graded depolarizations, $30 \mathrm{mV}$ of the spike amplitudes shown were cropped. $\boldsymbol{B}$, Mean spike number elicited by each sound stimulus (black) and PAD area (gray) averaged for 15 sequences of acoustic stimulation reveal a mismatch of spike activity and PADs for low and high frequencies. $\boldsymbol{C}$, Top trace, The spike rate of an afferent in response to acoustic stimulation between 3 and $20 \mathrm{kHz}$ (1 s pulses, $75 \mathrm{~dB}$ SPL). Middle trace, recording of the same afferent after spike generation of the ipsilateral ear was abolished by cooling. When the same sequence of acoustic stimuli was presented now only graded depolarizations were generated (average of 9 presentations). D, Mean spike number elicited by each sound stimulus (black) and PAD area (gray) analyzed for 9 sequences of acoustic stimulation. Whereas spike activity is maximum $\sim 5 \mathrm{kHz}$, PADs cover a range of $7-20 \mathrm{kHz}$. Error bars denote \pm 1 SD.

coinciding with PADs. Upon acoustic stimulation (white noise, $1 \mathrm{~s}, 75 \mathrm{~dB}$ SPL) a phasotonic burst of spikes with a mean spike rate of $180 \mathrm{~Hz}$ was elicited (Fig. 3B), accompanied by a depolarization of the afferent axon which persisted for the duration of the acoustic response. Throughout the response the reduction in spike amplitude was $6-12 \%$. It was particularly pronounced during highest spike frequencies at the beginning of stimulation (Fig. 3B, asterisk; up to $17 \%$ reduction) and coincided with an increased afferent depolarization. This indicates that as in other mechanosensitive systems (Clarac and Cattaert, 1996) PADs in bushcricket auditory afferents are linked to presynaptic inhibition.

Ipsilateral and contralateral sources of PADs

During white noise stimulation graded depolarizations were tightly coupled to spikes. The graded depolarizations, however, could also be elicited independent of spike activity when a wide range of frequencies was tested. A broadly tuned afferent responded with bursts of spikes upon stimulation with 4-18 $\mathrm{kHz}$. The spikes were riding on top of a pronounced and maintained depolarization (Fig. 4A). At $2 \mathrm{kHz}$ and also at 20 and 22 $\mathrm{kHz}$, however, the afferent depolarization occurred independent of spike activity as revealed by analyzing the PAD magnitude and spiking response over a series of stimuli (Fig. $4 \mathrm{~B}$ ). This demonstrated that spike activity in the afferent recorded was not necessary to elicit a graded depolarization in the same afferent.
We identified both the ipsilateral and the contralateral auditory pathway as sources of the PADs. Graded depolarizations were recorded in afferents when the contralateral ear was removed (data not shown). Graded depolarizations were also still present after we abolished spike activity either by removing the ipsilateral ear $(n=3)$ or by reversible cooling $(n=3)$ of the ear (Fig. $4 C$ ). Whereas the spiking response of the afferent in the intact animal was maximum $\sim 5 \mathrm{kHz}$, the contralaterally mediated PADs covered a range between 7 and $20 \mathrm{kHz}$ and did not match the spike tuning (Fig. 4D).

These approaches allowed to elicit the PADs independent from the generation of spikes. In the same afferent the approaches revealed a difference in the sound frequency tuning of the spike activity and that of the PADs as mediated centrally upon stimulating the contralateral ear (Fig. 4C,D). We further analyzed the different tunings of afferent activity and PADs using optical measurements of presynaptic $\mathrm{Ca}^{2+}$.

\section{$\mathrm{Ca}^{2+}$ signals as an indicator of PADs}

In the calyx of Held of the vertebrate central auditory pathway graded depolarizations due to a rise in $\mathrm{Cl}^{-}$conductance are linked to a rise in presynaptic $\mathrm{Ca}^{2+}$ levels (Turecek and Trussell, 2001; Awatramani et al., 2005). We therefore tested whether graded depolarizations in bush-cricket afferent terminals were also reflected in presynaptic $\mathrm{Ca}^{2+}$ changes. In the intact system the amplitude of the $\mathrm{Ca}^{2+}$ response to acoustic 
stimulation ( $75 \mathrm{~dB}$ SPL, white noise, 3 s duration) was $\sim 30 \%$ $\Delta F / F$ (Fig. 5, left). After the ipsilateral ear was removed all spikes were abolished. Nonetheless acoustic stimulation of the contralateral ear still elicited a $5 \% \Delta F / F$ rise in presynaptic $\mathrm{Ca}^{2+}$ (Fig. 5). This remaining $\mathrm{Ca}^{2+}$ signal therefore occurred under the same circumstances as the graded depolarization of the terminals elicited by contralateral acoustic stimulation. Results were consistent in 4 experiments in separate animals. PADs in insect sensory systems are often mediated by $\mathrm{GABA}_{\mathrm{A}}$ receptors controlling a $\mathrm{Cl}^{-}$conductance and it is blocked by picrotoxin (Burrows and Laurent, 1993; Trigo et al., 2008). Bath application of picrotoxin $\left(10^{-4} \mathrm{M}\right.$ in saline) reversibly blocked the remaining $\mathrm{Ca}^{2+}$ elevation in response to acoustic stimulation of the contralateral ear (Fig. 5, middle). We therefore propose that this $\mathrm{Ca}^{2+}$ response reflected the PADs in the afferent terminals.

The difference in the kinetics between the graded depolarizations as measured with the microelectrode and the optically measured $\mathrm{Ca}^{2+}$ signals are most likely the result of a slower change in $\mathrm{Ca}^{2+}$ levels in the axonal arborizations as well as the $\mathrm{Ca}^{2+}$ binding artifact introduced by the optical indicator.

\section{Sound frequency tuning of PADs}

To compare the sound frequency tuning of the intact afferent-as determined by the spiking response generated in the ear-with the frequency dependence of the contralaterally mediated graded depolarization, we used optical recordings. The $\mathrm{Ca}^{2+}$ signal was an indicator of afferent spike activity in the intact system (Fig. 2) as well as an indicator of the graded depolarizations when spike activity of the afferent was abolished (Fig. 5). As an advantage over microelectrode recordings the optical signal of $\mathrm{Ca}^{2+}$ indicators was easily maintained while the ipsilateral ear was removed. This revealed different frequency tunings of the spiking response and the PADs. For example a broadly tuned afferent that in the intact preparation responded to $5-20 \mathrm{kHz}$ with a best response at $12 \mathrm{kHz}$ received a graded depolarization of its axonal terminals at 16 and $20 \mathrm{kHz}$ (Fig. $6 \mathrm{~A}$, average of three presentations). Comparison of the peak $\mathrm{Ca}^{2+}$ responses before and after removal of the ipsilateral ear in 12 afferents revealed differences between their fre-

quency tuning and the PADs that were elicited by the contralateral auditory pathway (Fig. 6B). Results are shown from all 12 afferent recordings in which $\mathrm{Ca}^{2+}$ signals evoked by graded inputs were at least 3 SDs above the noise. Low-frequency afferents received PADs at high frequencies (Fig. $6 B_{1,2}$ ) while highfrequency afferents were inhibited at lower frequencies (Fig. $\left.6 B_{11,12}\right)$. Mid-frequency afferents, whose wide axonal arborization

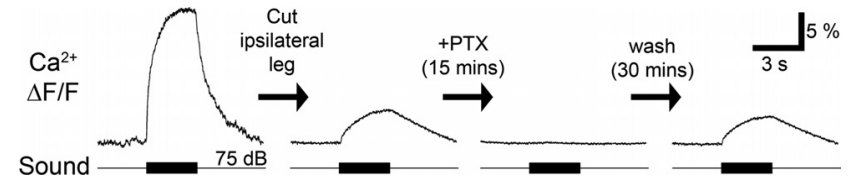

Figure 5. Imaging the $\mathrm{Ca}^{2+}$ signal during PADs. Acoustic stimulation with 3 s white noise at $75 \mathrm{~dB}$ SPL evoked a $30 \%(\Delta F / F)$ change in the $\mathrm{Ca}^{2+}$ signal in an intact auditory afferent. Removal of the ipsilateral ear decreased the response to $5 \%$. Bath application of picrotoxin (PTX) reversibly abolished this remaining response (average of 10 presentations each).

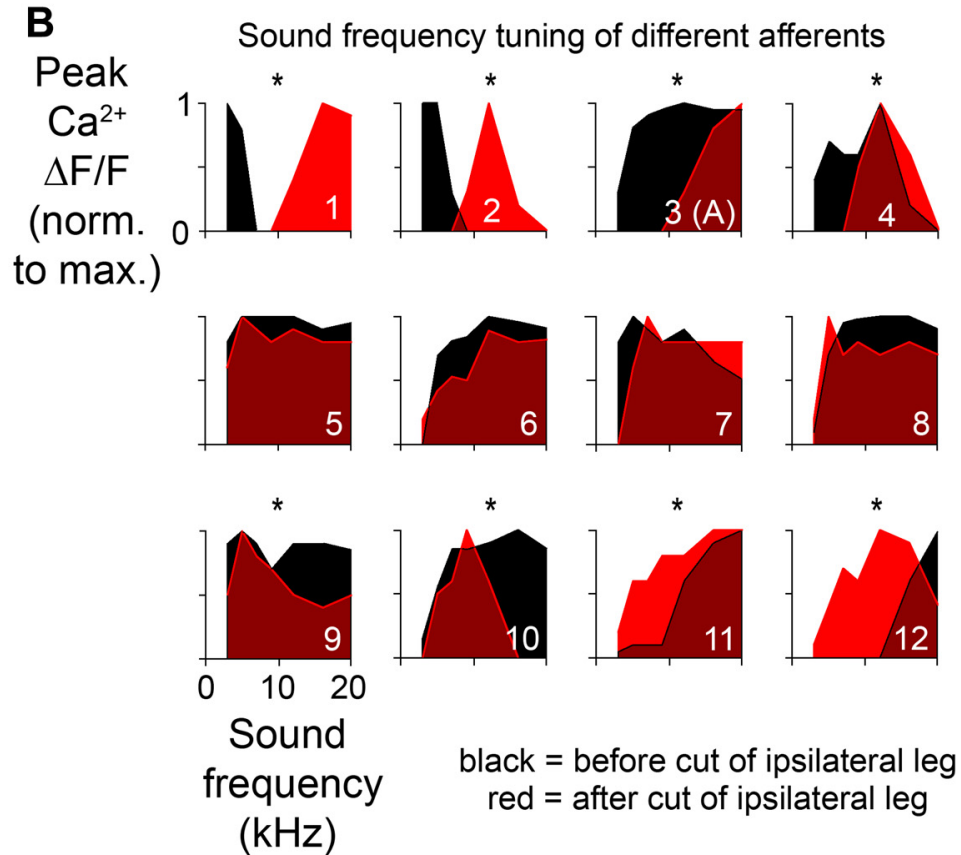

Figure 6. Frequency tuning of afferent spike activity and tuning of PADs. $A, \mathrm{Ca}^{2+}$ imaging revealed a broad frequency tuning of an auditory afferent in the intact system (top trace). After the ipsilateral ear was removed only responses to high-frequency sounds were elicited, revealing the different tuning of the PADs (middle trace). $\boldsymbol{B}$, Frequency tuning of afferents in the intact system (black) and tuning of the PADs (red) revealed by removal of the ipsilateral ear. Responses of 12 different auditory afferents are arranged according to their tuning in the intact system. Measurements are the averaged $\mathrm{Ca}^{2+}$ signals of 3 sound presentations. Asterisks indicate a significant difference in tuning curves as tested with Pearson's $\chi^{2}$ test. pattern spanned a large area of the neuropil (Fig. 1), could receive PADs which were tuned to either high (Fig. $6 B_{3,4}$ ), low (Fig. $6 B_{9,10}$ ) or to a wide range of frequencies (Fig. $6 B_{5-8}$ ), in the latter case with no clear difference in the tuning of spikes and PADs. In contrast to the tonotopic organization of auditory afferents the system mediating the PADs therefore appears to be organized with a reversed frequency gradient relative to the neuropil organization. 

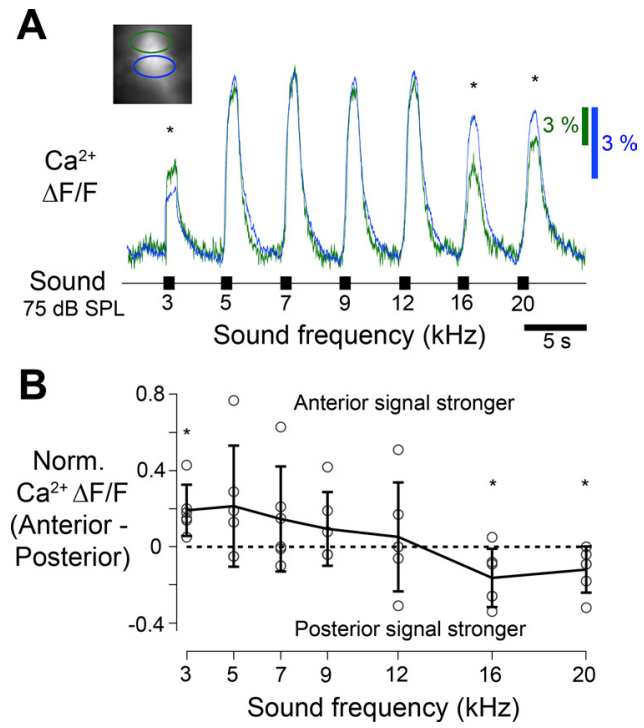

Figure 7. Frequency-specific responses of afferent axonal regions. $A$, A separate analysis of $\mathrm{Ca}^{2+}$ signals $(\Delta F / F)$ in response to acoustic stimulation was performed for anterior (green) and posterior (blue) regions of axonal arborizations of single mid-frequency afferents (inset) in the intact system. This revealed spatial differences in the responses to both high and low frequencies (asterisks). Low-frequency acoustic stimuli elicited stronger responses in the anterior region and high-frequency signals in the posterior region. Tuning curves were scaled to the maximum response measured in each region, average of 3 presentations. $\boldsymbol{B}$, Differences in the peak $\mathrm{Ca}^{2+}$ signal between the anterior and posterior regions at each frequency calculated for 6 mid-frequency afferents (error bars denote $\pm 1 S D$, asterisks denote a significant difference from zero, Student's $t$ test, $p<0.05$ ).

\section{Spatial organization of PADs in single afferents}

The wide axonal arborizations of mid-frequency afferents partially overlapped with the arborization of both low- and highfrequency afferents (Fig. 1). This provided an opportunity to test whether the spatial arrangement of the system mediating the PADs is indeed reversed when compared with the organization of frequency tuning in the afferents (Fig. 6B). Correspondingly anterior branches of mid-frequency afferents should receive predominately PADs at high-frequency acoustic stimuli, while posterior branches of the same cell should receive predominately PADs at low frequencies. As a consequence when comparing $\mathrm{Ca}^{2+}$ elevations in anterior and posterior branches of the same afferent in the intact system, anterior $\mathrm{Ca}^{2+}$ signals should be relatively smaller during acoustic stimulation with high frequencies, but posterior $\mathrm{Ca}^{2+}$ signals should be relatively smaller during acoustic stimulation at low frequencies, although all axonal terminals are invaded by the same spike pattern. We therefore stimulated mid-frequency afferents between 3 and $20 \mathrm{kHz}$ and compared the $\mathrm{Ca}^{2+}$ signals in anterior and posterior branches, scaled to their maximum responses, respectively (Fig. $7 A, B$ ). Differences in the anterior and posterior $\mathrm{Ca}^{2+}$ signals were revealed in response to both low-frequency and high-frequency acoustic stimuli. In the example shown the posterior region of the axonal arborizations responded 15\% weaker when low-frequency stimulation $(3 \mathrm{kHz})$ was presented whereas the anterior region responded up to $19 \%$ weaker during stimulation with highfrequencies $(20 \mathrm{kHz})$. Six of nine mid-frequency afferents analyzed in this way showed these spatial differences in the $\mathrm{Ca}^{2+}$ signal. We plotted the differences between anterior and posterior responses of these six cells against sound frequency. Positive values indicate stronger responses in anterior branches, while negative values indicate stronger responses in posterior branches (Fig. $7 B$ ). Stronger responses imply weaker inhibition, while weaker responses imply stronger inhibition. Therefore even in afferents where the spatially averaged tuning of PADs and spike activity was very similar (Fig. $6 B_{5-8}$ ) subcellular tuning differences were evident in anterior and posterior branches. These findings allow two conclusions. First, the spatial organization of sound frequency-dependent PADs observed at the subcelluar level matched the organization of PADs as observed in high- and lowfrequency afferents (Fig. 6): PADs evoked by high-frequency sound were present in the anterior regions of the auditory neuropil, while PADs evoked by low-frequency sound occurred in posterior regions. Second, if PADs were linked to presynaptic inhibition, depending on sound frequency different branches of individual afferents may forward auditory activity to interneurons with a different synaptic gain.

\section{Discussion}

Hearing organs in insects are based on chordotonal organs which are highly sensitive mechanoreceptors (Field and Matheson, 1998). In chordotonal afferents the occurrence of PADs linked to presynaptic inhibition and their role in shaping the flow of sensory activity is well established (Watson, 1992; Clarac and Cattaert, 1996, 1999; Watson et al., 2005). PADs in auditory afferents in singing crickets are mediated by a corollary discharge mechanism (Poulet and Hedwig, 2006), but otherwise the role of PADs in insect auditory information processing has not been analyzed. We demonstrated that PADs modulate the activity of bush-cricket auditory afferents and indicated their contribution to sound frequency processing.

\section{Organization of the auditory neuropil}

A frequency-specific arrangement of the auditory afferents exists in the bush-cricket Mecopoda elongata. This corresponds to the tonotopic organization of auditory neuropils in other bush-crickets. Low frequencies are represented in the anterior region and high frequencies in the posterior region of the neuropil (Oldfield, 1983; Römer, 1983; Römer et al., 1988; Stölting and Stumpner, 1998).

\section{PADs in afferent terminals}

Intracellular recordings close to the axon terminals of the auditory afferents revealed graded depolarizing synaptic inputs. Such inputs to sensory afferents were first characterized as PADs in the spinal cord of cats (Eccles et al., 1961). They were subsequently described in arthropod sensory systems and are closely linked to presynaptic inhibition (Blagburn and Sattelle, 1987; Boyan, 1988; Watson, 1992; Burrows and Laurent, 1993; Sauer et al., 1997; Clarac and Cattaert, 1996, 1999; Watson et al., 2005). GABAimmunoreactive synapses represent the majority of input synapses to the terminals of primary auditory afferent in bushcrickets and were interpreted as indicators of presynaptic inhibitory mechanisms (Hardt and Watson, 1999). As there were no direct synaptic contacts between the axonal arborization of different afferents (Hardt and Watson, 1999) and as the depolarizations of the terminals remained even after the ipsilateral ear was removed we conclude that these potentials were driven by central auditory interneurons. The reduced amplitude of spikes coinciding with PADs indicates that synaptic transmission from auditory afferents to interneurons in bushcrickets is subject to presynaptic inhibition.

As in other sensory systems (Ogawa et al., 2002; Galizia and Kimmerle, 2004; Baden and Hedwig, 2007; Moreaux and Laurent, 2007) $\mathrm{Ca}^{2+}$ signals in auditory afferents could be used as an indicator of spike activity. However, they also served as an indi- 
cator of the contralateral contribution toward PADs in the absence of spiking: both the graded depolarization and a $\mathrm{Ca}^{2+}$ signal in response to acoustic stimulation persisted after axonal spiking was abolished by removing or cooling the ipsilateral ear. Furthermore this $\mathrm{Ca}^{2+}$ signal was picrotoxin-sensitive and therefore dependent on the activation of $\mathrm{GABA}_{\mathrm{A}}$ receptors (Trigo et al., 2008), as PADs in other insect mechanoreceptors (Burrows and Laurent, 1993; Sauer et al., 1997). We conclude that both the graded depolarization and the $\mathrm{Ca}^{2+}$ response were indicators of the same presynaptic inhibition. The $\mathrm{Ca}^{2+}$ increase associated with PADs in the axonal branches may be due to low voltage activated influx of $\mathrm{Ca}^{2+}$ caused by the local depolarization (Awatramani et al., 2005) and/or it could be due to a local $\mathrm{Ca}^{2+}$ release from internal stores (Bootman et al., 2001).

Graded depolarizations in the axonal terminals of bushcricket auditory afferents may share functional similarities to the auditory system of rodents. In the nuclei of their auditory brainstem gradual depolarizations at the calyx of Held serve to mediate presynaptic inhibition in the millisecond range as well as to enhance vesicle release probability on a long time scale when the overall spike activity is low (Trussell, 2002; Awatramani et al., 2005; Trigo et al., 2008). Crucial to function is a depolarization of the terminals. This is mediated by the release of GABA or glycine causing a depolarizing shift in membrane potential of the terminals through an increased $\mathrm{Cl}^{-}$efflux. The resulting depolarization leads to an activation of $\mathrm{Ca}^{2+}$ channels and the increased $\mathrm{Ca}^{2+}$ level in the terminals in turn then contributes to modulating synaptic transmitter release. Such a twofold mechanism of the afferent depolarization could also operate in the bush-cricket auditory pathway.

\section{Frequency processing and PADs}

The bush-cricket auditory system allows the separation of ipsilaterally and contralaterally driven presynaptic activity of afferents through selective cooling or destruction of one ear. Afferents received PADs at sound frequencies that did not necessarily match the tuning of their own spiking response upon ipsilateral and contralateral acoustic stimulation. In the intact system spike activity masked both ipsi- and contralaterally driven PADs. However, abolishing spike activity by removal or cooling of an ear allowed to clearly identify the contralateral contribution to PADs. Low-frequency afferents received PADs at high frequencies, high-frequency afferents received PADs at low frequencies and mid-frequency afferents received PADs either tuned to low or high frequencies. In these cases PADs linked to presynaptic inhibition can sharpen the frequency tuning of synaptic transmission, similar to a sharpening of information processing in some arthropod mechanosensory systems (Watson, 1992). Other midfrequency afferents received PADs with a broad tuning. A match between the afferent tuning and the tuning of the PADs to the same afferent could indicate an overall frequency independent gain control of the synaptic output as described for chordotonal afferents of locusts (Burrows and Matheson, 1994). In addition presynaptic inhibition may not be only important for the processing of auditory stimuli from the environment but may shape the transmission of un-attenuated self-generated auditory activity during active sound production (Poulet and Hedwig, 2006). This may be of functional significance in afferents where the afferent tuning and the tuning of the PADs did not show any overlap at sound intensities tested.

However, even in the mid-frequency afferents PADs were spatially organized. Spike driven $\mathrm{Ca}^{2+}$ signals in anterior branches were larger in response to low-frequency acoustic stimulation whereas $\mathrm{Ca}^{2+}$ signals in posterior branches were larger in response to high-frequency stimulation. Accordingly, even in afferents where the overall tuning of PADs completely matched the spike tuning the frequency selective PADs of individual output branches resulted in a subcellular frequency tuning of synaptic transmission. Dendrite-specific processing revealed by $\mathrm{Ca}^{2+}$ signals has been described in many insect interneurons (Borst and Egelhaaf, 1992; Single and Borst, 1998; Baden and Hedwig, 2007; Ogawa et al., 2008). Furthermore, $\mathrm{Ca}^{2+}$ imaging of neuromuscular junctions of a single Drosophila melanogaster motoneuron revealed differences in synaptic gain along the muscle fiber (Guerrero et al., 2005). A spatially organized presynaptic modulation of activity in axonal arborizations of sensory neurons in vivo, however, has not been described before.

Our data also have implications for directional auditory processing since PADs of afferents were elicited by stimulating the contralateral ear. Bush-crickets discriminate interaural intensity differences of 1-2 dB SPL which are reliably represented at the level of the local omega neurons (Stradner and Römer, 2008). PADs linked to presynaptic inhibition mediated between the left and right auditory pathways may contribute to an auditory contrast enhancement and the directional processing of sound.

\section{Candidate interneurons mediating PADs}

The results indicate that the system mediating the PADs is organized with a frequency gradient opposite to the organization of the afferent axonal arborizations. Such frequency processing could in principle be mediated by direct synaptic contacts between terminals of neighboring afferents. However there is no ultrastructural or immunocytochemical evidence for such connections (Hardt and Watson, 1999). Alternatively it could be achieved at a subcellular level by mixed dendritic-axonal neurites of inhibitory interneurons with arborizations covering fractions of the auditory neuropil, in a similar way as formulated by Watson et al. (2005) for proprioceptive processing in crayfish. The short latency between spike activity and the generation of the afferent depolarization indicates a direct pathway. Some local auditory dorsal unpaired median neurons (Stritih and Stumpner, 2009) appear to have mixed dendritic and axonal projections covering the left and right auditory neuropil. They respond with short latencies to sound and may be suited candidates to mediate the PADs in the bush-cricket auditory system. Interestingly the frequency tuning of ascending bush-cricket auditory interneurons is picrotoxin-sensitive (Stumpner, 1998, 2002). Since, picrotoxin will also remove the PADs in the afferent pathway this may contribute to the altered tuning of these interneurons.

\section{References}

Awatramani GB, Price GD, Trussell LO (2005) Modulation of transmitter release by presynaptic resting potential and background calcium levels. Neuron 48:109-121.

Baden T, Hedwig B (2007) Neurite specific $\mathrm{Ca}^{2+}$ dynamics underlying sound processing in an auditory interneurone. J Neurobiol 67:68-80.

Baden T, Hedwig B (2009) Dynamics of free intracellular $\mathrm{Ca}^{2+}$ during synaptic and spike activity of cricket tibial motoneurons. Eur J Neurosci 29:1357-1368.

Bailey WJ, Rentz DCF (1990) The Tettigoniidae. Bathurst, Australia: Crawford House.

Blagburn J, Sattelle D (1987) Presynaptic depolarization mediates presynaptic inhibition at a synapse between an identified mechanosensory neurone and giant interneurone 3 in the first instar cockroach, Periplaneta americana. J Exp Biol 127:135-157.

Bootman MD, Collins TJ, Peppiatt CM, Prothero LS, MacKenzie L, De Smet P, Travers M, Tovey SC, Seo JT, Berridge MJ, Ciccolini F, Lipp P (2001) Calcium signaling-an overview. Semin Cell Dev Biol 12:3-10. 
Borst A, Egelhaaf M (1992) In vivo imaging of $\mathrm{Ca}^{2+}$ accumulation in fly interneurons as elicited by visual motion stimulation. Proc Natl Acad Sci U S A 89:4139-4143.

Boyan GS (1988) Presynaptic inhibition of identified wind-sensitive afferents in the cercal system of the locust. J Neurosci 8:2748-2757.

Burrows M, Laurent G (1993) Synaptic potentials in the central terminals of locust proprioceptive afferents generated by other afferents from the same sense organ. J Neurosci 13:808-819.

Burrows M, Matheson T (1994) A presynaptic gain control mechanism among sensory neurons of a locust leg proprioceptor. J Neurosci 14:272-282.

Clarac F, Cattaert D (1996) Invertebrate presynaptic inhibition and motor control. Exp Brain Res 112:163-180.

Clarac F, Cattaert D (1999) Functional multimodality of axonal tree in invertebrate neurons. J Physiol Paris 93:319-327.

Eccles JC, Eccles RM, Magni F (1961) Central Inhibitory action attributable to presynaptic depolarization produced by muscle afferent volleys. J Physiol 159:147-166.

Field LH, Matheson T (1998) Chordotonal organs of insects. Adv Insect Physiol 27:1-228.

Galizia CG, Kimmerle B (2004) Physiological and morphological characterization of honeybee olfactory neurons combining electrophysiology, calcium imaging and confocal microscopy. J Comp Physiol A Neuroethol Sens Neural Behav Physiol 190:21-38.

Guerrero G, Reiff DF, Agarwal G, Ball RW, Borst A, Goodman CS, Isacoff EY (2005) Heterogeneity in synaptic transmission along Drosophila larval motor axon. Nat Neurosci 8:1188-1195.

Gwynne DT (2001) Katydids and bush-crickets. Ithaca: Cornell UP.

Hardt M, Watson AH (1999) Distribution of input and output synapses on the central branches of bush-cricket and cricket auditory afferent neurons: Immunocytochemical evidence for GABA and Glutamate in different populations of presynaptic boutons. J Comp Neurol 403:281-294.

Knepper M, Hedwig B (1997) NEUROLAB, a PC-program for the processing of neurobiological data. Comput Methods Program Biomed 52:75-77.

Moreaux L, Laurent G (2007) Estimating firing rates from calcium signals in locust projection neurons in vivo. Front Neural Circuits 1:2.

Ogawa H, Baba Y, Oka K (2002) Spike-triggered dendritic calcium transients depend on synaptic activity in the cricket giant interneurons. J Neurobiol 50:234-244.

Ogawa H, Cummins GI, Jacobs GA, Miller JP (2006) Visualisation of ensemble activity patterns of mechanosensory afferents in the cricket cercal sensory system with calcium imaging. J Neurobiol 66:293-307.

Ogawa H, Cummins GI, Jacobs GA, Oka K (2008) Dendritic design implements algorithm for synaptic extraction of sensory information. J Neurosci 28:4592-4603.

Oldfield B (1983) Central projections of primary auditory fibres in Tettigo- niidae (Orthoptera: Ensifera). J Comp Physiol A Neuroethol Sens Neural Behav Physiol 151:389-395.

Poulet JF, Hedwig B (2006) The cellular basis of a corollary discharge. Science 311:518-522.

Römer H (1983) Tonotopic organisation of the auditory neuropile in the bushcricket Tettigonia viridissima. Nature 306:60-62.

Römer H, Marquart V, Hardt M (1988) Organization of a sensory neuropile in the auditory pathway of two groups of Orthoptera. J Comp Neurol 275:201-215.

Römer H, Hedwig B, Ott SR (2002) Contralateral inhibition as a sensory bias: the neural basis for a female preference in a synchronously calling bushcricket, Mecopoda elongata. Eur J Neurosci 15:1655-1662.

Root CM, Masuyama K, Green DS, Enell LE, Nässel DR, Lee CH, Wang JW (2008) A presynaptic gain control mechanism fine-tunes olfactory behavior. Neuron 59:311-321.

Sauer AE, Büschges A, Stein W (1997) Role of presynaptic inputs to proprioceptive afferents in tuning sensorimotor pathways of an insect joint control network. J Neurobiol 32:359-376.

Single S, Borst A (1998) Dendritic integration and its role in computing image velocity. Science 281:1848-1850.

Sobel EC, Tank DW (1994) In vivo $\mathrm{Ca}^{2+}$ dynamics in a cricket auditory neuron: an example of chemical computation. Science 263:823-826.

Stölting H, Stumpner A (1998) Tonotopic organization of auditory receptors of the bushcricket Pholidoptera griseoaptera (Tettigoniida, Decticinae). Cell Tissue Res 294:377-386.

Stradner J, Römer H (2008) Reliable coding of small behaviourally relevant interaural intensity differences in a pair of interneurons on an insect. Biol Lett 4:711-714.

Stritih N, Stumpner A (2009) Vibratory interneurons in the non-hearing cave cricket indicate evolutionary origin of sound processing elements in Ensifera. Zoology (Jena) 112:48-68.

Stumpner A (1998) Picrotoxin eliminates frequency selectivity of an auditory interneuron in a bushcricket. J Neurophys 79:2408-2415.

Stumpner A (2002) A species-specific frequency filter through specific inhibition not specific excitation. J Comp Physiol A Neuroethol Sens Neural Behav Physiol 188:239-248.

Trigo FF, Marty A, Stell BM (2008) Axonal GABA ${ }_{\mathrm{A}}$ receptors. Eur J Neurosci 28:841-848.

Trussell LO (2002) Modulation of transmitter release at giant synapses of the auditory system. Curr Opin Neurobiol 12:400-404.

Turecek R, Trussell LO (2001) Presynaptic glycine receptors enhance transmitter release at a mammalian central synapse. Nature 411:587-590.

Watson A, Le Bon-Jego M, Cattaert D (2005) Central inhibitory microcircuits controlling spike propagation into sensory terminals. J Comp Neurol 484:234-248.

Watson AH (1992) Presynaptic modulation of sensory afferents in the invertebrate and vertebrate nervous system. Comp Biochem Physiol Comp Physiol 103:227-239. 